\title{
Biological tissue graft for pelvic floor reconstruction after cylindrical abdominoperineal excision of the rectum and anal canal
}

\author{
C. L. Boereboom · N. F. S. Watson • \\ R. Sivakumar · N. G. Hurst · W. J. Speake
}

Published online: 18 July 2009

(C) Springer-Verlag 2009

Cylindrical abdominoperineal excision of the rectum and anus (APER) entails resection of the levator muscles en bloc with the lower rectum and anal canal, thereby reducing the incidence of circumferential resection margin involvement and intra-operative tumour perforations. Options for reconstruction of the resulting defect include myocutaneous flaps, which add significantly to the operating time, or biological tissue grafts. The series of images illustrate our method of tension free repair of the pelvic floor defect with a $7 \times 10 \mathrm{~cm}$ Surgisis ${ }^{\circledR}$ Biodesign $^{\mathrm{TM}}$ 4-layer tissue graft (Figs. 1, 2, 3, 4, 5, 6).

C. L. Boereboom · N. F. S. Watson $(\bowtie) \cdot$ R. Sivakumar · N. G. Hurst - W. J. Speake

Department of Colorectal Surgery, Derby City General Hospital, Uttoxeter Road, Derby DE22 3NE, UK

e-mail: nicholas.watson@ nottingham.ac.uk
Fig. 1 Cylindrical APER specimen containing low rectal tumour with en bloc resection of the mesorectum, anal canal and levator muscles
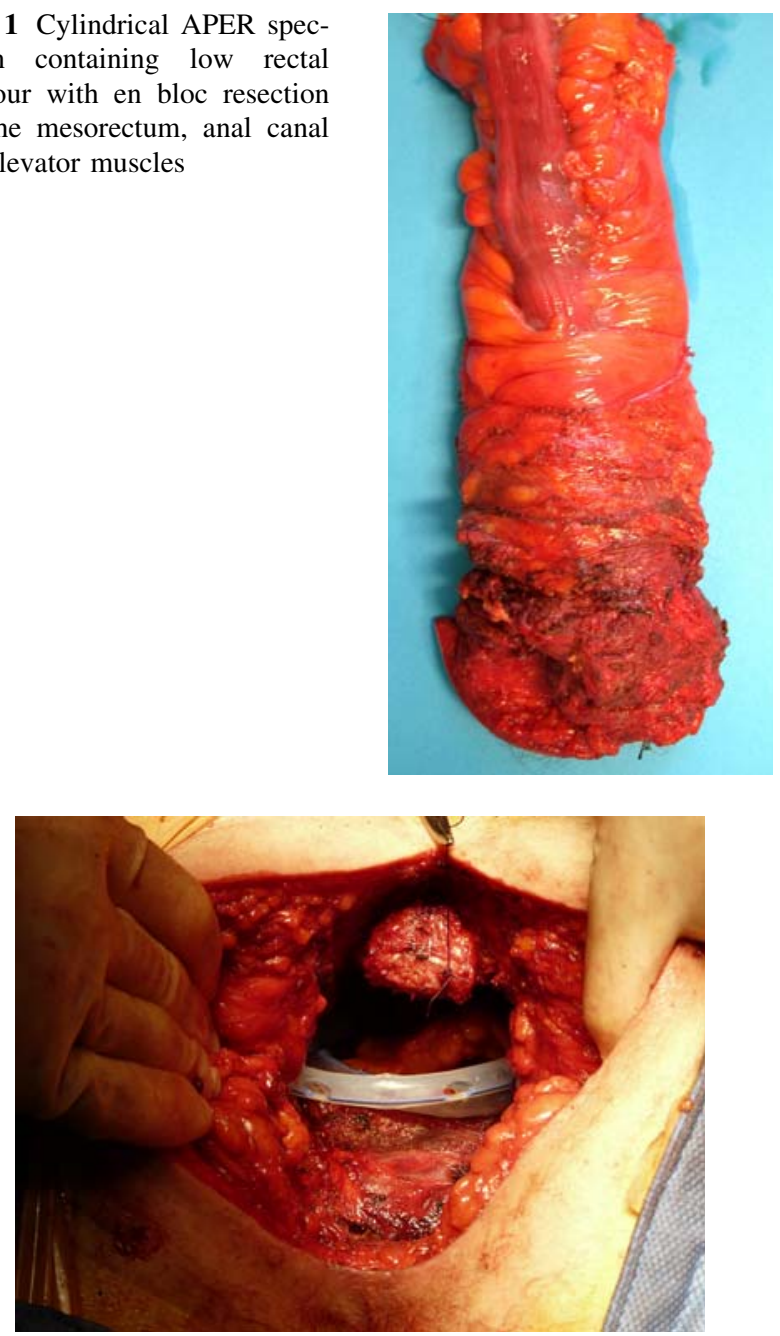

Fig. 2 The resulting pelvic floor defect is shown in the prone position, with sacrum superiorly, Denonvilliers' fascia over prostate inferiorly and ischiorectal fat laterally. Two abdominal gravity drains are visible in the pelvic cavity 


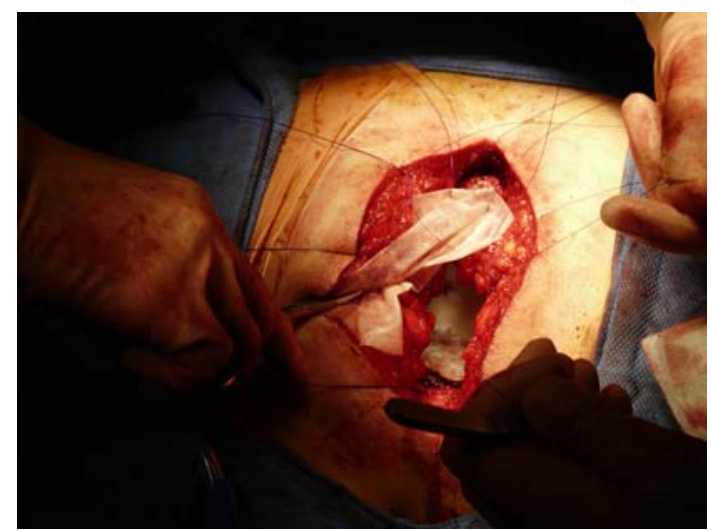

Fig. 3 The omentum and several sheets of Collatamp ${ }^{\circledR}$ G (EUSA Pharma) are placed in the pelvis after previous abdominal mobilisation. A $7 \times 10 \mathrm{~cm}$ Surgisis ${ }^{\circledR}$ Biodesign ${ }^{\text {TM }}$ 4-layer tissue graft is then secured to the margin of the pelvic floor as a parachute inlay using interrupted 2/0 PDS (Ethicon TM New Jersey, USA) sutures

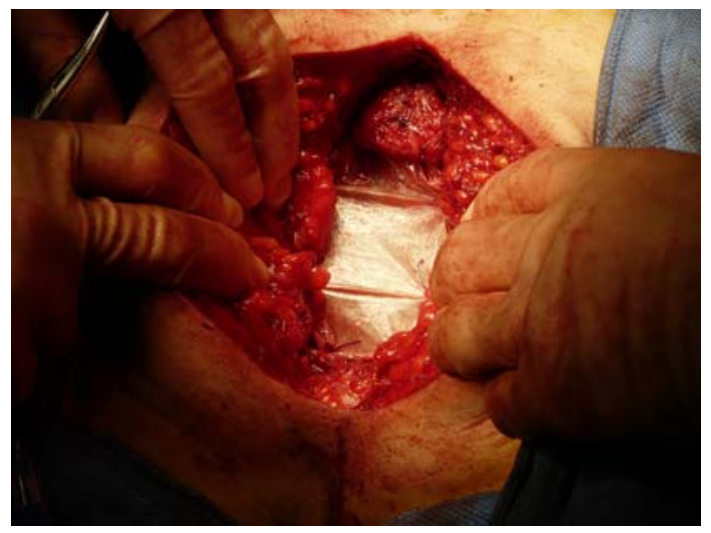

Fig. 4 The tissue graft seen in final position bridging the pelvic floor defect

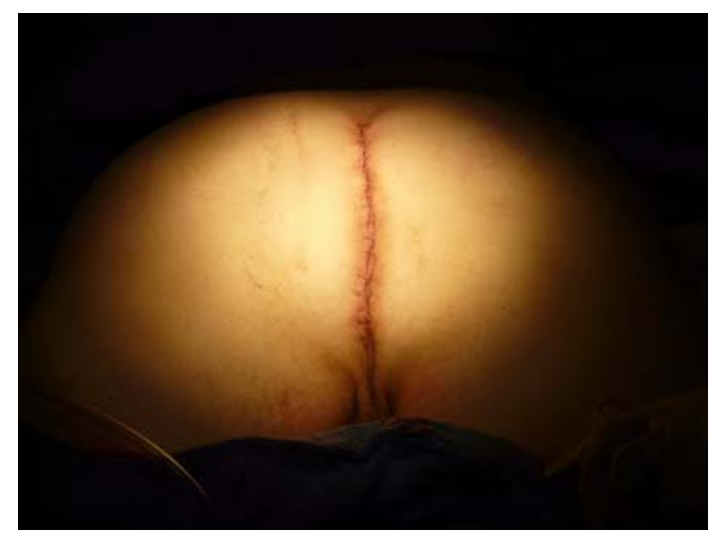

Fig. 5 The superficial layers are then closed with 1 Vicyrl and Vicryl rapide (EthiconTM)

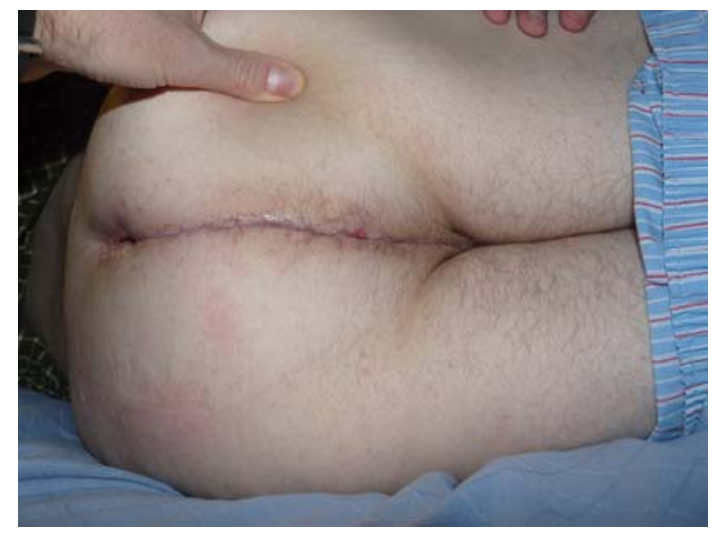

Fig. 6 Wound seen at 2 months post-surgery 